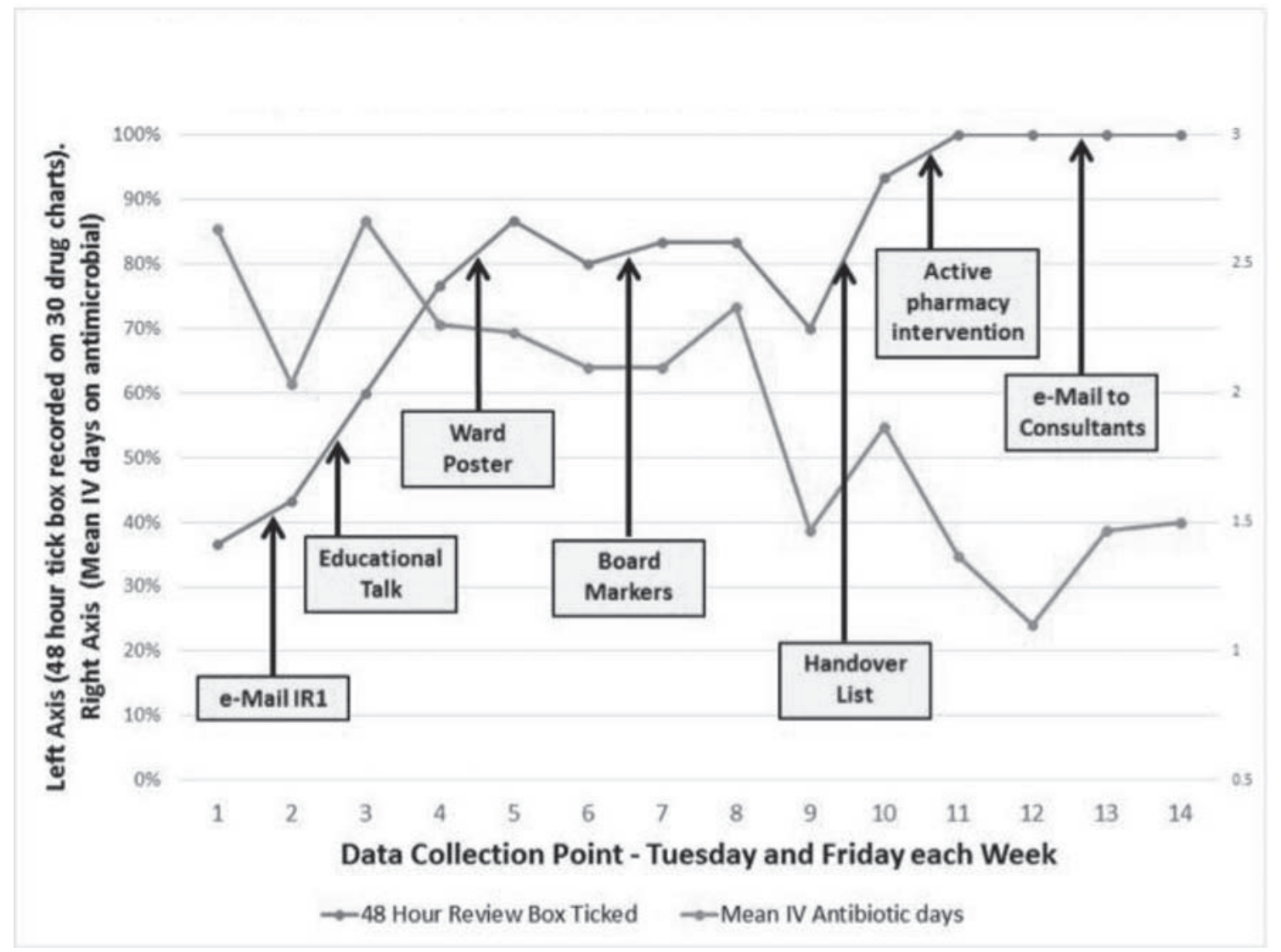

Abstract M8 Figure 1 Run chart displaying 48 hour review tick box and mean number of days on IV antimicrobials over 14 measurement cycles.

\section{M9 QUALITY IMPROVEMENT PROJECT: CAN WE IMPROVE RECORDING OF TARGET OXYGEN SATURATIONS AND PRESCRIBING ON A RESPIRATORY WARD IN ACCORDANCE TO NEW BRITISH THORACIC SOCIETY (BTS) OXYGEN GUIDELINES?}

RT Rahman, G Young, N Shah, B Reyad, A Choudhury. Barking, Havering and Redbridge University Hospital NHS Trust, Romford, UK

\subsection{6/thoraxjnl-2017-210983.431}

Introduction The BTS advises target oxygen saturations of $\geq 94 \%$ for all adult patients excepting those at risk of hypercapnic respiratory failure - where oxygen should be restricted to achieve saturations of $88 \%-92 \%{ }^{1}$. In the 2015 BTS audit however, although $14 \%$ of all UK inpatients received oxygen, only half of these patients had a prescription and 30\% had oxygen delivered inappropriately.

Method and Objective We aimed to improve oxygen prescribing and setting of target saturations on drug charts with appropriately delivered and monitored oxygen therapy. Our main outcome measure was that "In $90 \%$ of cases, oxygen saturations recorded on nursing observation charts will match prescription on drug chart”. 15 patient records were sampled weekly from an acute respiratory ward over three months. Process measures were: i) Is oxygen prescribed on the drug chart? ii) Are target saturations recorded on the drug chart? 48 hour antibiotics review was the balancing measure. Five PDSA interventions took place; a) an educational announcement b) poster c) weekly email showing ward performance d) pharmacist prescription reviewing target ranges and e) displaying target saturations at patient bedsides.

Results Eleven cycles of data were collected. Of 165 medical case notes reviewed, the three most common respiratory conditions were COPD-35\%, pneumonia-21\% and lung cancer$11 \%$. $22 \%$ had no respiratory condition as presenting complaint or previous history. On admission, 20\% were hypercapnic on arterial blood gas. At baseline, only $46 \%$ of drug charts had completed oxygen prescriptions and 66\% target saturations. Following PDSA interventions this peaked to $100 \%$. Our outcome measure, do oxygen saturations on observation charts match target saturations on drug charts, improved to nearly 90\% from initial baseline 53\% (figure 1). Conclusion This QIP has shown that simple interventions can improve oxygen prescribing and appropriate delivery, although our target of $90 \%$ is yet to be achieved. The PDSA intervention with the most positive effect on the outcome measure was sharing our improvements via email to the entire ward team. We aim to sustain these Results beyond this project with further PDSA interventions and implement these practices in other acute and general medical wards within the hospital. 